\title{
A FILOSOFIA DA MENTE DE PLATÃO E A IMORTALIDADE DA MENTE: UM DUALISMO SUBSTANCIAL
}

The philosophy of mind of Plato and the immortality of mind: a dualism substantial

\author{
Márcio Francisco Rodrigues Filho*
}

Resumo: Este ensaio de filosofia tem como objetivo apresentar o que se entende por dualismo substancial em filosofia da mente. Para tanto, utilizarei a teoria filosófica do "primeiro" dualista sobre o caráter do mental de que se tem notícia na história da filosofia, Platão. Inicialmente, apresento a filosofia da mente e suas concepções basais para introduzir o que se entende por dualista nesta área e posteriormente adentrar em uma explicação mais profunda sobre o dualismo substancial. Após, apresento os principais aspectos da teoria da mente de Platão, demonstrando por que ela é um exemplo desse tipo de dualismo substancial e analiso um dos argumentos platônicos em favor da imortalidade da alma, exposto na obra A república, como exemplo, para mostrar que ele não é capaz de estabelecer o que propõe. Por fim, esboço algumas considerações finais ao retomar os principais aspectos analisados no decorrer deste ensaio.

Palavras-chave: Dualismo Substancial. Filosofia da Mente. Imortalidade da Alma. Platão. República.

\begin{abstract}
This philosophy paper aims to present what is meant by substantial dualism in the philosophy of mind. Therefore, I will use the philosophical theory of "first" on the dualistic character of mental ever heard in the history of philosophy, Plato. First introduce the philosophy of mind and its conceptions baseline to introduce what is meant by this dualistic area, later to enter into deeper explanation about the substantial dualism. After I present the main aspects of Plato's theory of mind by demonstrating that it is an example of this type of dualism and analyze one of the Platonic arguments in support of the immortality of the soul exposed in the work The Republic to show that he is unable to establish what it proposes. Finally, we outline some final remarks by recalling the main aspects analyzed during this paper.
\end{abstract}

Keywords: Substantial Dualism. Philosophy of Mind. Immortality of the Soul. Plato. Republic.

* Mestrando do Programa de Pós-graduação em Filosofia da Universidade do Vale do Rio dos Sinos (UNISINOS) Bolsista CAPES. Contato: marcio.francisco.rodrigues@gmail.com

\begin{tabular}{|c|c|c|c|c|c|}
\hline intuitio & $\begin{array}{c}\text { ISSN } \\
1983-4012\end{array}$ & Porto Alegre & Vol.7 - No.2 & $\begin{array}{c}\text { Novembro } \\
2014\end{array}$ & p.89-103 \\
\hline
\end{tabular}




\section{A filosofia da mente e o dualismo substancial}

A filosofia da mente, com seus 63 anos, pode ser considerada um dos ramos mais novos da filosofia. Isso porque é costumeiramente inaugurada em 1949, ano em que Gilbert Ryle ${ }^{1}$ publica um livro intitulado The concept of mind, mas, embora as questões de debate da filosofia da mente perpassem por toda a história do pensamento ocidental ${ }^{2}$ devido as suas questões de grande abrangência, é uma área vista como relativamente nova. Digo isso porque em filosofia da mente, geralmente, os problemas estão divididos em duas instâncias que não podemos afirmar serem tão jovens quanto a própria filosofia da mente; de um lado, temos os problemas ontológicos, quando nos perguntamos Qual a natureza de nossos processos mentais? Onde eles ocorrem e como se relacionam com o mundo físico? Minha mente sobreviverá depois da minha morte ou desaparecerá quando meu cérebro parar de funcionar? De onde vêm as mentes, o que são elas? De outro lado, temos os problemas epistemológicos, isto é, aqueles que dizem respeito ao modo pela qual podemos conhecer as mentes, com perguntas como Será que podemos conhecer as mentes, e como podemos fazer isso? Existem outras mentes além das nossas, como poderemos saber? Nossas mentes são iguais? Um computador pode pensar? Como distinguir as mentes de seres humanos de zumbis, alienígenas ou computadores? Será que estes últimos têm mentes? Ambas questões, sejam as epistemológicas ou as antológicas, sempre fizeram parte do cardápio filosófico; e para clarear algumas dessas questões que demonstram que a filosofia da mente é um estudo imerso em questões filosóficas debatidas há muito tempo - mas que carrega consigo uma nova roupagem, uma vez que as ferramentas de investigação cerebral têm avançado de maneira significativa nos últimos anos ${ }^{3}-$, apresentarei algumas questões basais da filosofia da mente, para posteriormente, apresentar o que se entende por dualismo substancial dentro deste "novo" ramo filosófico.

Quero que você imagine um ponto laranjae reflita. Se pudéssemos abrir seu cérebro, poderíamos encontrar essa "imagem", esse ponto laranja? E o mesmo ponto laranja que você pensou poderia ser comparado com o ponto laranja que estou a pensar? Como saberemos se o ponto laranja que lhe pedi pra pensar é maior, menor, ou do mesmo tom de laranja do que o ponto que pensei ao pedir para que você pensasse? Para dificultar, será que os pontos laranja (que você pensou e que eu pensei) são da mesma cor? Ou, ainda, será que você ou eu chegamos a pensar em um ponto laranja?

\footnotetext{
${ }^{1}$ Renomado filósofo que lecionou em Oxford da década de 20 a década de 60 do século passado. Criticou duramente o dualismo cartesiano em sua maior obra, The concepto $f$ mind (MATTHEWS, Eric. Mente: conceitos-chave em filosofia. Porto Alegre: Artmed, 2007, p. 65).

${ }^{2}$ COSTA, Claudio. Filosofia da mente. Rio de Janeiro: Jorge Zahar, 2005, p. 7.

${ }^{3}$ Isso possibilitou investigar o alicerce neural onde ocorrem as atividades psicológicas de animais e humanos. Agora não contamos apenas com papel e caneta, pois temos o PET (Positron Emission Tomography) e o fMRI (Functional Magnetic Resonance Imaging) como ferramentas importantíssimas para o estudo do cérebro. "Não é mais possível falar de memória, consciência e de outros fenômenos mentais como se fazia a sem anos, pois agora eles são investigados empiricamente" (TEIXEIRA. Filosofia do cérebro. São Paulo: Paulus, 2012, p. 15).

\begin{tabular}{|c|c|c|c|c|c|}
\hline intuitio & $\begin{array}{c}\text { ISSN } \\
1983-4012\end{array}$ & Porto Alegre & Vol.7 $-\mathrm{N}^{\mathrm{o} .2}$ & $\begin{array}{c}\text { Novembro } \\
2014\end{array}$ & p.89-103 \\
\hline
\end{tabular}
}


Sabemos que estamos pensando, mas ambos, você e eu, não podemos observar nossos pensamentos de maneira objetiva, até porque nem sequer podemos ver nossos cérebros, assim como não podemos ver também o que está ocorrendo agora com nossos rins e pulmões, para não falar no nosso sangue. Se não podemos comparar aquilo que pensamos com algo público, observável, que se encontra na natureza, teremos que aceitar que tais pensamentos, isto é, estados mentais, são, nada mais, nada menos, do que estados subjetivos, que parecem contrariar aquilo que é tido como objetivo, público, observável, "na terceira pessoa". Você até poderá apontar para um ponto laranja no mundo objetivo e dizer "este é o ponto em que pensei", mas não poderemos saber se a cor é exatamente a mesma que eu vejo. Aprendemos as cores perguntando, por exemplo, "que cor é essa?" e obtendo respostas do tipo "essa cor é verde, essa é azul, essa é laranja", etc. Porém, nada impede que a cor que apreendi como sendo azul, seja aquela que você via como sendo laranja. Agora, você me mostra um ponto laranja e eu enxergo um ponto azul, mesmo concordando com você que vejo um ponto laranja ${ }^{4}$. O mesmo acontece em relação as nossas dores. Não temos como compará-las a nada público nesse "mundo da terceira pessoa" e dizer "Olhe essa geladeira! Você está vendo esse pequeno ponto de ferrugem aqui na porta? Essa é a intensidade da dor que lhe falei que estou sentido após ter batido com o martelo no meu dedo!”. Digo essas coisas, porque se abrirmos nossos cérebros, não iremos enxergar o ponto laranja, nem as nossas dores ali, mas apenas um órgão biológico feito de carne, algo químico e físico. Caso ampliássemos esse órgão, enxergaríamos apenas nossos neurônios e a tempestade elétrica provocada por eles nas sinapses e, obviamente, não veríamos um ponto laranja "tatuado" ali. Por essa razão, os pensamentos são considerados estados subjetivos, algo que não encontramos na natureza, mas sim, "dentro de nós”. Não vemos nossos pensamentos impressos no cérebro, mas sabemos que, se nosso cérebro for alterado por algo, como, por exemplo, algum tipo de droga, nossa percepção também ficará alterada. A droga é física e interage com corpos físicos; logo, ela também interage com o cérebro. Se cortarmos uma parte " $X$ " do cérebro de alguém e essa pessoa parar de enxergar, deduziremos que essa é a parte do cérebro responsável pela visão. Isso sugere que o cérebro tem alguma relação com a mente. Porém, que tipo de relação é essa?

Quando nos perguntamos como esses estados subjetivos - que parecem ser "coisas acessíveis" apenas a nós mesmos, em primeira pessoa (subjetividade) - se relacionam com os estados objetivos, publicamente observáveis em terceira pessoa (cérebro), estamos envolvidos com o problema mais debatido em filosofia da mente: o problema mente-corpo (hoje entendido como "mente-cérebro").

\footnotetext{
${ }^{4}$ Embora essa questão seja visivelmente retórica, ainda assim ela é importante, pois para um cético dizer que que a cor é material, ou seja, é um fenômeno "provocado pela ação de um feixe de fótons sobre células especializadas da retina, as quais transmitem impressões para o sistema nervoso, permitindo diferenciar os objetos do espaço com maior precisão" ainda assim, não explicaria se a cor que você vê é ou não a mesma que eu vejo (COR: FENÔMENO ÓTICO. Universidade Federal do Pará, PR, Abr. 2009. Disponível em:< http://www.ufpa.br/dicas/htm/htm-cor4.htm.>. Acesso em 28 jan. 2013).
}

\begin{tabular}{|c|c|c|c|c|c|}
\hline intuitio & $\begin{array}{c}\text { ISSN } \\
1983-4012\end{array}$ & Porto Alegre & Vol.7- $\mathrm{N}^{\mathrm{o} .2}$ & $\begin{array}{c}\text { Novembro } \\
2014\end{array}$ & p.89-103 \\
\hline
\end{tabular}


Qual é a natureza do mental e sua relação com o corpo (cérebro)? $?^{5}$ Em filosofia da mente, há duas maneiras de pensar sobre esse problema:

\begin{abstract}
Uma diz que só existe o cérebro e que a mente é, na verdade, uma ilusão. Outra diz que existem duas coisas, a mente e o cérebro e que este apenas abriga à primeira, ou seja, que o cérebro é apenas o hospedeiro biológico da mente. A primeira posição é chamada de monismo materialista, ou simplesmente materialismo. A segunda é chamada de dualismo, pois aposta na existência de duas coisas distintas: mente e a matéria (cérebro) (TEIXEIRA, 2008, p. 10).
\end{abstract}

Dentro dessas duas vertentes, existem outras muitas teorias de explicação sobre o mental, mas ambas ou são dualistas ou materialistas: behaviorismo analítico $^{6}$, Teoria da identidade ${ }^{7}$, Funcionalismo $^{8}$, entre outras. O dualismo substancial ${ }^{9}$ é uma das vertentes teóricas sobre o mental e, como seu nome mesmo sugere, ela é uma teoria dualista sobre o problema mente-cérebro. Assim como as demais teorias sobre o mental, o dualismo substancial procura responder se há uma relação entre a mente e o corpo (mente e cérebro), e que tipo de relação é essa.

Por esse motivo, a filosofia da mente surge na metade do século XX, justamente para tentar resolver esse problema (mente-cérebro). No livro de Gilbert Ryle, The concepto of mind, o autor sustenta que esse seria um pseudo problema, porque ele surge de uma ideia equivocada de mente, parida da linguagem. Nessa concepção, a mente é tomada como um fantasma na máquina. Quando digo "minha mente está cansada", tomo minha mente como um objeto, uma coisa, e não como um conceito. "Estou aplicando um vocabulário físico ao mental, pois meus músculos podem ficar cansados, mas minha mente não" (TEIXEIRA, 2012, p. 63). Essas passagens de um campo ao outro, de um conceito para um objeto, como no caso da mente, quando tomamo-nas como objeto e não como conceito, criando uma ideia de que estados mentais são uma substância. Porém, para Ryle, tal

${ }_{6}^{5}$ COSTA, Claudio. Filosofia da mente. Rio de Janeiro: Jorge Zahar, 2005, p. 15.

${ }^{6}$ Uma espécie de reação contra a corrente dualista. Para um behaviorista analítico o mental entendido como um conjunto de entidades subjetivas e privadas não desempenha papel algum. Conceitos como, dor, prazer, desejo, raiva, entre outros, "devem ser analisados em termos de comportamentos ou disposições para se comportar" (COSTA, Claudio. Filosofia da mente. Rio de Janeiro: Jorge Zahar, 2005, p. 19). Ao tentarmos explicar porque uma pessoa escolheu fazer tal coisa estaríamos dizendo que ela estava propensa a realizar tal ação dado o significado daquilo que ela fez.

${ }^{7}$ Movimento independente surgido nos Estados Unidos e na Austrália por volta de 1950. Para os pensadores desta corrente, propriedades mentais são propriedades cerebrais, ou seja, materiais. "Os teóricos da identidade, contudo, argumentam que qualquer propriedade mental é na realidade uma propriedade física" (HEIL, John. Filosofia da mente: uma introdução contemporânea. Porto Alegre: Instituto Piaget, 1998, p. 101).

${ }^{8}$ Uma herança do behaviorismo onde a característica essencial do mental se como um conjunto de relações causais que o pensamento mantém em três estâncias: 1. Relações causais com os efeitos do meio ambiente sobre o corpo. 2. Relações causais de uns pensamentos com os outros. 3. Relações causais com o comportamento corporal. "O objetivo de tal trabalho é descobrir em detalhe a organização funcional que faz de nós o que somos" (CHURCHLAND, Paul M. Matéria e consciência: uma introdução contemporânea à filosofia da mente. São Paulo: Editora UNESP, 2004, p. 71). Para um funcionalista as mentes podem ser comparadas a softwares de computador e os cérebros os hardwares que rodam esses programas (mentes).

${ }^{9}$ Segundo Maslin, o dualismo substancial é aquele que apresenta duas coisas que podem existir por si mesmas "contrastando com o que pode ser dito delas, ou estar em elas. A distinção entre estar em e ser dito de pode ser aplicada do seguinte modo: sorrisos qualificam-se como "particulares", isto é, como itens individuais. Por exemplo, pode haver um sorriso de João, um sorriso de Maria, e assim por diante, e são sorrisos em sujeitos" (MASLIN, K. T. Introdução à filosofia da mente. 2. Ed. Porto Alegre: Artmed, 2009, p. 40).

\begin{tabular}{|c|c|c|c|c|c|}
\hline intuitio & $\begin{array}{c}\text { ISSN } \\
1983-4012\end{array}$ & Porto Alegre & Vol.7- $\mathrm{N}^{\mathrm{o} .2}$ & $\begin{array}{c}\text { Novembro } \\
2014\end{array}$ & p.89-103 \\
\hline
\end{tabular}


deturpação poderia ser corrigida através da identificação de alguns erros linguísticos ocorridos através da criação indevida de um vocabulário físico e mental que transgride categorias. Uma espécie de exorcismo da linguagem poderia ser feito pela filosofia, afinal, tais transgressões, poderiam ser identificadas, e o problema mente-cérebro, desfeito, pois não passaria de um erro linguístico criado pelos filósofos ao tratarem da mesma coisa de forma diferente. No entanto, vejamos, agora, como, de fato, esse tipo particular de dualista, o dualista substancial, toma o ser humano.

Para esse tipo de dualista, os humanos são compostos de duas entidades distintas: corpo e alma (ou mente). O corpo é físico e a alma é uma entidade não-física. Quando estamos vivos, esta alma (mente), de alguma forma, afeta o corpo e vice-versa; porém, com a morte do corpo, a alma se separa e continua a existir sem precisar do corpo. A morte física, nesse aspecto, portanto, não é o fim, porque não resulta no término de nossa consciência e de tudo aquilo que carregamos na nossa subjetividade - que, aliás, é aquilo que mais valorizamos em nossas vidas, ou deveríamos valorizar, já que consta como sendo o que vemos, ouvimos, sentimos cheiramos e lembramos. Por isso, um dualista substancial poderia dizer que não vemos o ponto laranja ao olhar para o cérebro, porque o ponto laranja é um produto da alma, que é invisível e é incorporada por Deus, ou alguma outra entidade em nossos corpos quando o espermatozoide fecunda o óvulo.

As religiões, ou pessoas que seguem alguma religião, geralmente, são difusoras desse tipo de doutrina sobre o mental. Essa visão faz, de forma incontestável, parte de nossa cultura e de nossa linguagem do dia-a-dia. Note que transladamos e enterramos corpos - corpos apenas, sem suas mentes - e rezam-se missas por intenção das almas que estiveram nesses corpos” (TEIXEIRA, 2008, p. 19). A hipótese de nossas mentes (almas) continuarem vivas após a morte é algo que se apresenta como atraente, porque possibilita a ideia de continuarmos existindo após a nossa morte, mesmo que meramente num plano subjetivo, isto é, puramente mental. Bons exemplos desse plano subjetivo, dado pelas religiões, são o céu e o inferno. Lá "vivem" as almas (mentes) que desencarnaram dos corpos após a morte e agora desfrutam do resultado daquilo que plantaram enquanto estiveram viajando nas "naves corporais" e mortais durante sua estadia na terra. Porém, a fim de mostrar o dualismo substancial carrega alguns problemas, para aludir esses problemas, valerei-me de um argumento a cerca da imortalidade da alma exposto no livro $X$ da República de Platão ${ }^{10}$.

Antes de dizer, então, o que considero estar errado com o argumento de Platão em favor do dualismo substancial, gostaria de explanar alguns pontos sobre as questões mentais da obra de Platão, uma vez que neste ensaio abordarei apena um dos muitos argumentos de Platão em favor de sua teoria dualista que buscava entre outras coisas comprovar a imortalidade da alma.

\section{$2 \mathrm{O}$ dualismo substancial platônico}

${ }^{10}$ Mesmo que a base da crítica tecida a Platão nesse ensaio possa ser estendida de forma generalizada a qualquer dualista substancial (como algo aparentemente imaterial pode se relacionar causalmente com coisas materiais?), aqui me deterei à análise de um único argumento platônico em favor do dualismo substancial.

\begin{tabular}{|c|c|c|c|c|c|}
\hline intuitio & $\begin{array}{c}\text { ISSN } \\
1983-4012\end{array}$ & Porto Alegre & Vol.7- $\mathrm{N}^{\mathrm{o} .2}$ & $\begin{array}{c}\text { Novembro } \\
2014\end{array}$ & p.89-103 \\
\hline
\end{tabular}


Segundo (2009), Platão (c. 427-347 a.C) é um dos principais nomes do dualismo, mesmo não tendo sido ele o filósofo a cunhar o termo. Até o que sabemos, foi Platão o primeiro a apresentar uma teoria escrita que buscava comprovar o dualismo. O filósofo grego acreditava na sobrevivência à morte por meio da alma, bem como na pré-existência desta antes do nascimento. A alma ${ }^{11}$, isto é, a mente, para Platão, estava envolvida de forma íntima com as essências ou arquétipos perfeitos, atemporais, imutáveis, que eram os moldes e formas originais das coisas. Tais formas originais estavam situadas no mundo inteligível, assim como a alma. Essas essências e moldes originais existiam por si só "acima do mundo dos sentidos, e só podem ser apreendidas pelo intelecto após um rigoroso treinamento em matemática e filosofia"12.

O livro VII da república de Platão é um bom meio de mostrar sua teoria das essências, uma vez que ele nos apresenta, através do mito da caverna, como o nossa mente (alma) pode ser treinada para captar as formas e os moldes originais das coisas (o mundo na sua forma perfeita e sem distorções como é o caso do mundo dos sentidos). Nesta alegoria Platão nos apresenta alguém (um filósofo) que se liberta da prisão do mundo sensível, dos sentidos do corpo, e conhece a verdade do mundo inteligivel.

Por meio do personagem Sócrates, Platão procura demonstrar qual é a condição humana relativa à inteligência e à ignorância. Para tal, pede para que imaginemos uma morada subterrânea, em forma de caverna, com apenas uma entrada de luz. Lá se encontram homens acorrentados desde criança, que não podem nem se quer mover seu pescoço, pois as correntes que os amaram impede qualquer movimento. A luz vem de uma fogueira que está muito longe, atrás desses homens. Entre essa fogueira e os homens ainda se encontra uma parede. Atrás dessa parede passam pessoas carregando coisas, objetos, animais, uns homens falam outros não. E uma vez que os homens que estão dentro da caverna estão presos sem mover-se e a única coisa que enxergam são as sombras a sua frente e o eco dos sons distorcidos nas suas costas, Sócrates conclui que esses homens só atribuem realidade as sombras que podem ver a sua frente ${ }^{13}$. E aqui se encontra o ponto nevrálgico, porque para Platão a alma deve ser desviada das coisas que se alteram e voltar-se para o inteligível onde se encontra a ideia do bem, pois "pensar é ao que parece, de um caráter mais divino, do que tudo o mais, nunca perde a força" ${ }^{\prime \prime}$.

Assim, é preciso notar que, para Platão, é exatamente através dessa participação nas formas que as coisas (comuns, imperfeitas, mutantes e perecíveis) se tornam aquilo que são - como o fato de uma flor ser como é, por exemplo, uma rosa ter sua cor vermelha, se deve a maneira como ela deveria

${ }^{11}$ Tratarei nesse ensaio o conceito alma como análogo ao conceito de mente. Assim como o faz Maslin em seu livro introdutório sobre a filosofia da mente (MASLIN, K. T. Introdução à filosofia da mente. 2. Ed. Porto Alegre: Artmed, 2009, p. 39).

${ }_{12}$ MASLIN, K. T. Introdução à filosofia da mente. 2. Ed. Porto Alegre: Artmed, 2009, p. 41.

${ }^{13}$ PLATÃO. A República. Lisboa: Fundação Calouste Gulbenkian, 2001, 514a-b.

${ }^{14}$ PLAT ÃO. A República. Lisboa: Fundação Calouste Gulbenkian, 2001, 318e.

\begin{tabular}{|c|c|l|l|c|c|}
\hline intuitio & $\begin{array}{c}\text { ISSN } \\
1983-4012\end{array}$ & Porto Alegre & Vol.7- $\mathrm{N}^{\circ} .2$ & $\begin{array}{c}\text { Novembro } \\
2014\end{array}$ & p.89-103 \\
\hline
\end{tabular}


se relacionar com sua matriz, a rosa perfeita habitante do "mundo das ideias". Isso acontece porque a teoria das formas de Platão apresenta um mundo de características universais, que como já dito, só poderá ser aprendido após um forte treinamento por meio da geometria, matemática e filosofia, pois o mundo que vemos a nossa volta não é perfeito como esses universais que são a verdadeira forma das coisas.

Para Platão, vivemos num mundo de aparências de coisas mutáveis que são pobremente percebidas pelos nossos sentidos. Contrariando o mundo dos universais, como diz Maslin (2009), esse seria o mundo dos particulares, cópias imperfeitas, ou apenas reflexões dos universais. Dessa forma, em Platão, "conhecimento é familiaridade com as Formas não-sensórias, crença é familiaridade com particulares sensórios" (MASLIN, 2009, p. 292). Por isso, dizemos que Platão é adepto ao dualismo, pois para ele, a alma, isto é, a mente tem sua natureza análoga a das formas universais que é algo diferente dos particulares, mesmo que seja a mente a via de acesso para um e outro mundo a mente é imortal, pois quando morremos ela volta a se juntar com as formas perfeitas de onde foi derivada.

Assim, a alma, ao ver de Platão, se parece com as verdadeiras formas. Isso porque a alma se caracteriza como "divina, imortal, inteligível, indissolúvel, invariável constante em relação a si própria" ${ }^{\prime 15}$. A mente é diferente das coisas perecíveis, por não habitar o mundo dos sentidos. Vemos claramente que o argumento de Platão favorece a interpretação de que corpo e a alma são substancialmente $^{16}$ diferentes. Platão possui um grande número de argumentos ao longo de toda a sua obra em que ele concebe a alma como uma entidade não-física e a mente (estados subjetivos da pessoa) é identificada com a alma. Como mencionado, apresentarei apenas um, extraído de sua obra $A$ república, para análise, por uma questão prática e didática, uma vez que esse é um argumento relativamente bem conhecido e pode ajudar a entender como um religioso poderia justificar a imortalidade da sua mente dizendo que quando morrer carregará consigo tudo aquilo que possui na sua subjetividade.

\section{Um argumento platônico em favor da imortalidade da alma}

No livro $X$ da república de Platão, encontramos um argumento em favor da imortalidade da alma. Através deste argumento, procurarei demonstrar que Platão se compromete com uma perspectiva dualista substancial em filosofia da mente e que seu argumento em favor desse tipo de teoria, se analisado por menormente, é fraco.

${ }^{15}$ PLATÃO. Phaedro, 80a-b. In: Hamilton, E. and Cairns. Eds. The colletcted Dialogues of Plato, Princeton, Princeton University press, $80 \mathrm{~b}$.

${ }^{16}$ De acordo com Maslin, em filosofia, uma substância é algo que pode existir por si mesma, com independência lógica de todas as outras coisas, diferente das propriedades que tem de ser características de uma ou outra coisa. "Contudo, assim como as propriedades precisam pertencer as substâncias, pareceria igualmente que não podem existir substâncias sem características ou propriedades. Substâncias e propriedades são feitas uma para a outra. É um casamento feito no céu metafísico que nenhum filósofo pode separar" (MASLIN, K. T. Introdução à filosofia da mente. 2. Ed. Porto Alegre: Artmed, 2009, p. 294).

\begin{tabular}{|c|c|c|c|c|c|}
\hline intuitio & $\begin{array}{c}\text { ISSN } \\
1983-4012\end{array}$ & Porto Alegre & Vol.7- $\mathrm{N}^{\mathrm{o} .2}$ & $\begin{array}{c}\text { Novembro } \\
2014\end{array}$ & p.89-103 \\
\hline
\end{tabular}


Pelo que sabemos, o corpo é mortal, apodrece e se deteriora, assim como todas as coisas que sabemos habitar o tempo e o espaço. Assim, se a alma é imortal, ela é radicalmente diferente do corpo, dado que não carregaria as mesmas propriedades, pois as mentes (almas) seriam substancias lógicas diferentes dos corpos materiais. O argumento de Platão carrega algumas particularidades, como bem notou Ryle ao apresentar alguns aspectos da filosofia cartesiana em sua obra The concept of mind. Parece claro que, assim como era para Platão, também o foi para Descartes (1596-1650) ${ }^{17}$, isto é, essa marcante diferença entre o físico e o mental parece levar a uma diferença entre a estrutura comum das categorias, pois a mente aqui é sem dúvida tomada como sendo uma coisa, mas uma coisa de espécie bem diferente do corpo (RYLE, 1970, p. 19). Embora a mente, em Platão, seja a mediadora entre o mundo inteligível e o mundo sensível, ainda assim, sua forma pertenceria aos universais e por isso seria perfeita, imutável e eterna. A mente, sob essa perspectiva, é uma substância radicalmente diferente do corpo, que é uma substância que nasce, cresce e morre, se deteriora, começa e termina se transformando em outras formas, assim como todas as coisas que pertencem ao mundo dos sentidos.

A apresentação do argumento surge no diálogo platônico do livro $X$ da República quando o personagem Sócrates faz uma comparação entre vícios da alma e doenças do corpo. Segundo ele, doenças estas que não são do corpo, pois se manifestam no corpo. Sócrates procura demonstrar através de uma série de analogias que se existem doenças que prejudicam o corpo, então deve haver vícios prejudiciais à alma (mente) uma vez que são "realidades" distintas.

Baseado na premissa de que algo só pode ser destruído por uma coisa que seja de sua própria natureza, Sócrates conclui, assim, que a alma é imortal, porque segundo ele, aquilo que é da própria natureza da alma não é capaz de destruí-la. Ele aceita o fato de o corpo ser destruído por doenças (algo que faz parte da natureza do corpo), isto é, um vício do corpo (as doenças), é um fato que serve como hipótese de que a alma (mente) também deve sucumbir a um vício próprio. Mas se a doença, que é algo da própria natureza do corpo, portanto, é um vício que pode destruí-lo, então, deve haver um vício da própria natureza da alma, que seja capaz de destruí-la. Se tal afirmação for confirmada (o fato da alma ser destruída por um vício de sua própria natureza), a alma seria mortal - do contrário, seria imortal. Porém, a alma, como procurará argumentar Platão através do personagem Sócrates, não poderá sucumbir diante dos seus vícios, que são o mal próprio de sua natureza ${ }^{18}$. Platão procura

${ }^{17}$ Foi médico, matemático, geômetra e filósofo. Inventou a geometria analítica e descobriu o comportamento reflexo e que o pensamento ocorre no cérebro (algo que não se tinha certeza no século XVII). Nas suas Meditações metafísicas de 1641, apresentou três argumentos em favor de seu dualismo (mente e corpo são coisas distintas. $1^{\circ} \mathrm{Se}$ o corpo e alma fossem a mesma coisa, quando amputo um membro do corpo também deveria estar amputando uma parte da mente, mas não é como sabemos, isso que ocorre. $2^{\circ} \mathrm{A}$ mente é mais fácil de conhecer do que o corpo, pois o acesso a mente não precisa ser mediado por nada (o conhecimento da mente é imediato). $3^{\circ} \mathrm{O}$ físico e o mental são totalmente diferentes, "pois qualquer coisas extensas no espaço (como é o caso dos corpos) é infinitamente divisível. Não teria cabimento dizer que poderíamos cortar um pensamento ou uma crença da mesma maneira que cortamos uma fatia de pão" (TEIXEIRA, João de Fernandes. Como ler filosofia da mente. São Paulo: Paulus, 2008, p. 16). Para Descartes, pensamentos não são coisas extensas e por isso, eram radicalmente diferentes da matéria.

${ }^{18}$ PLATÃO. A República. Lisboa: Fundação Calouste Gulbenkian, 2001, 609 a-b-c-d.

\begin{tabular}{|c|c|c|c|c|c|}
\hline intuitio & $\begin{array}{c}\text { ISSN } \\
1983-4012\end{array}$ & Porto Alegre & Vol.7 $-\mathrm{N}^{\circ} .2$ & $\begin{array}{c}\text { Novembro } \\
2014\end{array}$ & p.89-103 \\
\hline
\end{tabular}


demonstrar sua hipótese a partir da premissa que uma coisa só pode ser destruída por vícios que forem de sua própria natureza.

Assim sendo, se os vícios da alma não prejudicam a alma, que é exatamente aquilo que carrega os vícios, assim como o corpo é aquele que carrega a doença, então a alma não é afetada, não se deteriora diante dos vícios. Isso porque os vícios, que são o mal próprio da alma, que são da natureza da alma, afirma Sócrates, parecem prejudicar apenas os outros e não a própria alma, que é "aquilo" que carrega os próprios vícios. Os vícios da alma são praticados por meio da ação daquele que está corrompido pelos vícios. É a corrupção da alma, que atinge a terceiros por meio da ação, e não a própria alma. Esta hipótese, segundo Sócrates, demonstra que a alma não é vítima de destruição pelos vícios de sua própria natureza, uma vez que um homem não morre ao praticar um ato injusto.

Agora, veja-se como o personagem Sócrates no livro de Platão procura nos convencer dessa afirmação de que a alma não pode ser destruída pelo vício da sua própria natureza. Sócrates começa explicar aquilo que ele entende como sendo o mal e o bem. "Tudo que destrói e corrompe é mal, ao passo que o que salva e preserva é bom"19. Para cada coisa que existe, existe também um bem e um mal, diz Sócrates. Assim sendo, há um mal e uma doença para cada coisa. A podridão para a madeira, a ferrugem para o ferro, a doença para o corpo etc ${ }^{20}$. O argumento de Sócrates é bem claro. Ele quer demonstrar que existe um mal, isto é, uma "doença" natural (que nasce) em cada coisa assim, o mal surgiria da doença, por exemplo. Por isso, Sócrates dirá que quando um mal sobrevém ${ }^{21} \mathrm{em}$ cada coisa (esse vício de sua própria natureza) deteriora aquela coisa em que mal surgiu destruído esta coisa completamente. Nas palavras de Sócrates "o mal e o vício próprios da natureza de cada coisa, é que deitam a perder cada uma; ou, se não for isso que a deita a perder, não há outra coisa que possa destruí-la" ${ }^{22}$. Dito isso, Sócrates sugere que se encontrarmos um ser que seu mal o corrompe, mas não é capaz de dissolvê-lo ou destruí-lo, poderemos dizer que este ser, ou seja, a coisa que o mal corrompe não é capaz de destruí-lo, pois tal ser seria indestrutível, ou seja, imortal. E como já dito anteriormente, uma vez que o vício próprio da alma não é capaz de destruí-la, mas apenas modifica-la por meio da ação, esse ser imortal, dirá Sócrates, é a alma. Porque o vício, isto é, a doença da alma que é capaz de corrompê-la, por exemplo, não a destrói, uma vez que nenhum homem ao tornar-se corrupto, por exemplo, morre.

\footnotetext{
${ }^{19}$ PLATÃO. A República. Lisboa: Fundação Calouste Gulbenkian, 2001, 608e.

${ }^{20}$ PLATÃO. A República. Lisboa: Fundação Calouste Gulbenkian, 2001, 609.a.

21 Dando continuidade ao esclarecimento de alguns conceitos filosóficos sobre o mental, superveniente/subveniente de acordo com Maslin são um fenômeno que surge de uma base subveniente e dela depende para sua existência. "Além disso, não podem ocorrer mudanças no fenômeno superveniente com uma correspondente mudança na base subveniente, mas o oposto não é válido devido à possibilidade de uma realização múltipla do fenômeno superveniente por uma variedade de bases subvenientes. A natureza exata dessa relação superveniente é controversa" (MASLIN, K. T. Introdução à filosofia da mente. 2. Ed. Porto Alegre: Artmed, 2009, p. 294).

${ }^{22}$ PLATÃO. A República. Lisboa: Fundação Calouste Gulbenkian, 2001, 609b.

\begin{tabular}{|c|c|l|l|c|c|}
\hline intuitio & $\begin{array}{c}\text { ISSN } \\
1983-4012\end{array}$ & Porto Alegre & Vol.7- $\mathrm{N}^{\mathrm{o}} .2$ & $\begin{array}{c}\text { Novembro } \\
2014\end{array}$ & p.89-103 \\
\hline
\end{tabular}
}


Antes de sugerir que tal ser é propriamente a alma, isto é, a mente, aquilo que se ocupa do intelecto, Sócrates se indaga se a alma pode ser tornar má, pois precisa provar assim como explanou sobre os vícios do corpo, que estes são corrompidos por vícios de sua própria natureza, que agora, de forma análoga, a mente também seja corruptível. Dessa questão, obtém uma resposta positiva, porque segundo Sócrates, muitas coisas podem tornar a alma má (a injustiça, a intemperança, a covardia, ignorância, etc) ${ }^{23}$. Porém, para Sócrates, o mal da alma pode torná-la corrupta, mas não destruí-la porque os vícios podem corrompê-la e não destruí-la. Porque um sujeito que comete uma injustiça e é insensato não se desfaz, deteriorando-se até a morte ao praticar um ato injusto. O que quer dizer que $o s$ vícios da alma não podem destruí-la. Já que, nas observações de Sócrates, essa alma, quando afetada por seu mal, faz emergir na alma determinado vício que acarretara numa ação corrompida e não na morte da alma que se torna corrupta. Por isso, Sócrates se questiona quando o sujeito pratica "por ventura a injustiça, e demais vícios que nela existem, pelo fato de permanecerem arraiais nela, a destroem e fazem murchar, até que levam a morte, separando-a do corpo?"24.

Como resposta, conclui o óbvio - que não -, pois o que torna a alma má não pode matá-la e separá-la do corpo, já que apenas altera sua conduta, ou seja, seu "funcionamento". Logo, o vício da alma não poderá destruí-la, pois só um vício de sua própria natureza pode se encarregar desse fim e, uma vez que tal fim não pode ser levado a cabo, então, a alma é entendida como imortal. Essa explanação nos encoraja a pensar que a alma é imortal, mas, como veremos, as coisas não precisam ser aceitas assim, tão facilmente, da maneira como Platão sugere em seu diálogo.

Seguindo o mesmo argumento de Sócrates, um alimento estragado pode fazer mal à saúde, mas é o mau (podre) do alimento que faz mal a doença do corpo. É o podre do alimento que faz emergir a doença, é o mal da doença que afeta o corpo. Não é o alimento que faz mal ao corpo e sim o vício do alimento, isto é, a podridão, e, consequentemente, esta podridão, que é um vício de natureza do alimento, será aquilo que afeta a doença do corpo. Essa doença, por sua vez, que é o vício do corpo, será aquilo que afeta o corpo. Portanto, o mal do corpo não provoca na alma o mal da alma, porque nada é destruído por algo alheio a sua própria natureza. Como o mal do corpo não é, segundo Sócrates, um vício da própria natureza da alma, ele (o mal do corpo: a doença) não poderá afetá-la. Sócrates aponta para a existência de uma relação causal, pelo que parece, nesse sentido, entre coisas de "sua própria natureza", já que uma coisa perece somente por meio do seu mal e não pelo mal da outra. Assim como a fruta apodrece por causa de uma mal de sua própria natureza, assim como acontece com o corpo no caso da doença, a alma só poderá ser destruída por um mal, isto é, por um vício, de sua própria natureza. Mas, como já vimos, de acordo com Sócrates, isso não acontece. Uma vez que

${ }^{23}$ PLATÃO. A República. Lisboa: Fundação Calouste Gulbenkian, 2001, 609b-c.

${ }^{24}$ PLATÃO. A República. Lisboa: Fundação Calouste Gulbenkian, 2001, 609d.

\begin{tabular}{|c|c|c|c|c|c|}
\hline intuitio & $\begin{array}{c}\text { ISSN } \\
1983-4012\end{array}$ & Porto Alegre & Vol.7 $-\mathrm{N}^{\mathrm{o} .2}$ & $\begin{array}{c}\text { Novembro } \\
2014\end{array}$ & p.89-103 \\
\hline
\end{tabular}


alguém, mal, ruim, injusto, não morre por praticar tais vícios da alma. Sócrates dirá mais, que o padecimento do corpo não pode deixar a alma injusta ou ímpia e nos convida a provar o contrário ${ }^{25}$.

Agora, vejamos; será que alguém sofrendo de câncer, ou de uma doença terminal, não poderia em consequência disto praticar atos injustos, ou será que alguém não poderia sofrer por amor, ou ainda, morrer de desgosto, ou de depressão? A Platão importa mostrar que uma vez que a perversidade e o mal próprio da alma não podem matá-la e sim, apenas corrompe-la, isto é, muda-la, o mal da alma pode mudar à alma (alterar a ação por meio da corrupção) e não matá-la. Porque segundo Platão se assumirmos a sua premissa: uma coisa só pode ser destruída por vícios que forem de sua própria natureza. Teremos de concluir que os vícios da alma não podem destruí-la já que podem apenas corrompe-la o que parece provar que a alma é imortal. Em fim, o argumento platônico em favor da imortalidade da alma pode ser formalizado e resumido do seguinte modo:

1. Uma coisa só pode ser destruída por vícios que forem de sua própria natureza (Suposição) isto é, um vício destrói uma coisa apenas se for um vício de sua natureza (como a doença destrói o corpo, e a doença e um vício do corpo). Vícios não destroem naturezas que lhes são estranhas.

2. O vício natural da alma é a injustiça.

3. A injustiça é incapaz de matar a alma - afinal, os homens continuam vivos mesmo sendo injustos, ou após a prática de atos injustos (Fato).

4. O vício natural da alma é incapaz de matá-la.

5. Conclusão: a alma é imortal.

Mas o argumento assim apresentado é notadamente inválido, pois nessa forma em que é apresentado por Platão, a conclusão se segue da premissa, porém, ainda assim, o argumento é formalmente válido. Isso porque a primeira premissa é visivelmente falsa, pois ela diz que vícios só são destrutivos para aquilo de que são fonte como vício. As doenças são defeitos do corpo; elas não destroem a alma, nem destroem coisas que não são orgânicas. Disso não segue que eventos ou ocorrências acidentais não podem destruir algo. O corpo pode ser destruído por doenças, mas pode ser destruído por incidentes externos (que não são vícios, portanto, do corpo). Ou seja, para Platão os vícios só matam aquilo do qual são vícios, o que não é verdade, o vício das pessoas em diversas drogas, por exemplo, podem levá-las a morte, mas o vício de uma pessoa, não poderá aniquilar os outros vícios que esta pessoa tem. Se um indivíduo é viciado em crack e cocaína, ele não poderá usar um desses vícios, para aniquilar o outro. Embora, aquilo que é morto por um vício pode obviamente morrer de outras causas e um exemplo disso, é que o corpo tanto pode ser morto por um vício quanto por um tiro, ou, ainda, pelo atropelamento motivado por um caminhão. Logo, a conclusão de Platão a respeito da imortalidade da alma segue-se das premissas, mas uma das premissas é notavelmente, como acabamos de ver, falsa. O vício da alma pode ser de fato incapaz de matá-la, mas disso não se

${ }^{25}$ PLATÃO. A República. Lisboa: Fundação Calouste Gulbenkian, 2001, 610b.

\begin{tabular}{|l|c|c|c|c|c|}
\hline intuitio & $\begin{array}{c}\text { ISSN } \\
1983-4012\end{array}$ & Porto Alegre & Vol.7- No.2 & $\begin{array}{c}\text { Novembro } \\
2014\end{array}$ & p.89-103 \\
\hline
\end{tabular}


segue que a alma é imortal, porque aquilo que é morto por um vício pode morrer de outras causas, como é o caso do corpo, que tem relação causal com todas as formas materiais.

O argumento de Platão em favor da imortalidade da alma só é válido se a primeira premissa for tomada numa versão mais forte, a saber, de que algo somente (e apenas somente) pode ser destruído pelo que é vício de sua própria natureza. Isto é, algo só entra em relação causal por meio dos vícios de sua própria natureza. Mas se fizermos isso, teremos de aceitar a premissa como sendo verdadeira de antemão. O problema é que essa suposição é flagrantemente falsa. O argumento é, portanto, é formalmente válido, mas a conclusão decorre de premissas falsas. Pode ser na versão mais forte, válido, mas ainda assim é falso, pois o argumento não demonstra que a alma é imortal, não através daquilo que ele procura afirmar.

Sabemos que nossos estados subjetivos, isto é, nossos pensamentos são estados privamos e que não podemos compará-los com nada público e observável. Imagine apontar para uma fechadura e dizer que o gosto do sorvete de morango que eu estou tomando é idêntico a isto. Seria um absurdo. As pessoas não poderiam entender nossos estados de dor ou prazer, se comparássemos com qualquer coisa do mundo público e observável na terceira pessoa, no entanto, isso não significa que nossa mente seja algo totalmente diferente dos nossos corpos. Se assim fosse, como poderia existir uma relação possível entre nossas mentes e nossos corpos? Essa é uma questão difícil de ser respondida. Seja para um monista estritamente materialista que insiste que existem apenas cérebros e as mentes são uma ilusão, ou para um dualista substancial, como é o caso de Platão. Não sabemos de fato o que é a mente e o que a produz, mas sabemos que se nossos cérebros forem afetados nossas mentes também serão. Pense em uma droga usada no combate a dor, fortíssima, chamada morfina. Uma pessoa que recebeu uma dose de morfina, esta sedada e certamente tem suas percepções alteradas. Seus estados mentais nem sempre correspondem com a realidade. Por vezes, estes estados mentais são alucinações provocadas pelo medicamento. A morfina é uma substância física, assim como o cérebro e por isso, se relaciona com o cérebro. Não é porque não enxergamos nossas "imagens" mentais impressas no cérebro que devemos concluir que essas "imagens", nossos estados subjetivos, são algo radicalmente diferente do nosso corpo, ou do nosso cérebro, algo que não é físico, por exemplo.

Ficaria difícil responder por meio de uma teoria como a de Platão como uma notícia ruim poderia me dar uma azia. Como tal relação causal se estabeleceria? Como que poderia movimentar meu corpo através da minha vontade (como algo não físico, o querer, que é uma manifestação da alma, da mente, como pensou Platão, poderia entrar numa relação causal com meu cérebro e fazer com que eu me movimente)? Como explicar que uma substância totalmente diferente daquilo que entendemos como físico poderia se relacionar com nosso cérebro e explicar os movimentos dos meus dedos que digitam esse trabalho, através da minha vontade de escrevê-lo? Principalmente nos dias de hoje, que já sabemos que notícias ruins podem nos levar não apenas a uma depressão, mas também aumentar nossos batimentos cardíacos, nos levando a um infarto. E ainda, como uma corrente de

\begin{tabular}{|c|c|c|c|c|c|}
\hline intuitio & $\begin{array}{c}\text { ISSN } \\
1983-4012\end{array}$ & Porto Alegre & Vol.7 $-\mathrm{N}^{\circ} .2$ & $\begin{array}{c}\text { Novembro } \\
2014\end{array}$ & p.89-103 \\
\hline
\end{tabular}


frustrações causaria uma depressão? E como sabemos hoje, "o cérebro dos deprimidos sofre alterações profundas" ${ }^{26}$. Questões deste tipo seriam praticamente inexplicáveis se tomarmos o dualismo substancial como uma resposta ao problema mente-corpo.

\section{Considerações finais}

Mesmo que o argumento de Platão em favor da imortalidade da alma apresentado no capítulo $X$ da república não possa estabelecer que a alma seja imortal, pois decorre de premissas falsas, ainda assim, $\mathrm{O}$ argumento é extremamente útil para cumprir o objetivo deste ensaio. Que é mostrar o que a filosofia da mente entende por dualismo substancial. Pude demonstrar que dentro dessa perspectiva filosófica sobre o mental se encontram duas substancias lógicas radicalmente diferentes, a saber: corpo (matéria) e alma (universal, imutável, a mente).

Acredito que a interpretação de Platão sobre o mental esteja ligada aquilo que Ryle chamou de erro-categoria, ao se referir ao dualismo cartesiano. Segundo Ryle, os filósofos falaram sobre o "eu", especulando que este fosse "uma substância peculiar e à parte, em que consiste a minha identidade contínua e indivisível” ${ }^{, 27}$. Esse eu, o homem, a identidade, para Platão, era propriamente a alma de cada um, isto é, sua mente. Porém, é necessário notar que mesmo que expressões que façam referência a pessoas e ao corpo de pessoas não tenham o mesmo significado, isso não quer dizer que corpo e aquilo que as pessoas são, isto é, sua alma (mente ou "eu"), sejam substâncias lógicas totalmente diferentes. Muitas vezes falamos da mesma substância lógica, mas nos referimos a substância como contendo um significado diferente. Um exemplo que pode nos ajudar a compreender isso é dado por Maslin, que diz que quando afirmamos algo como, por exemplo: "eu vi Patrício à noite passada" tem um significado diferente de: "eu vi o corpo de Patrício na noite passada". Afinal, isso acontece porque quando vemos Patrício, queremos dizer que o vemos vivo e quando falamos do corpo, queremos dizer que seu organismo parou de funcionar, só isso e nada a mais. Assim, isso não significa que estamos nos referindo à outra coisa totalmente diferente de Patrício. Porque não existe nada em nosso vocabulário, ou seja, em nosso jeito de se expressar que se possa estabelecer qualquer dualismo ${ }^{28}$.

É importante notar que o dualismo e a separação entre a mente e o corpo assim como vemos no argumento de Platão exposto nesse trabalho, não percorre somente toda a longa história da filosofia ocidental, mas é também um assunto que está ferrenhamente atrelado ao nosso linguajar cotidiano. E por isso, é importante que se tenha uma discussão aprofundada sobre o assunto. Afinal, é através dessa "separação" entre mente e corpo, que damos sentidos a muitas coisas que acontecem em nossas experiências do dia a dia. E nem sempre estamos certos daquilo que dizemos, mas fazemos. Ainda que

${ }^{26}$ TEIXEIRA, João de Fernandes. Como ler filosofia da mente. São Paulo: Paulus, 2008, p. 12.

27 RYLE, Gilbert. Introdução à psicologia: o conceito de espírito, The concept of mind. Lisboa: Moraes Editores, 1970, p. 185.

${ }^{28}$ MASLIN, K. T. Introdução à filosofia da mente. 2. Ed. Porto Alegre: Artmed, 2009, p. 46.

\begin{tabular}{|c|c|c|c|c|c|}
\hline intuitio & $\begin{array}{c}\text { ISSN } \\
1983-4012\end{array}$ & Porto Alegre & Vol.7 $-\mathrm{N}^{\mathrm{o}} .2$ & $\begin{array}{c}\text { Novembro } \\
2014\end{array}$ & p.89-103 \\
\hline
\end{tabular}


nossos atos de fala criem "coisas", situações que não existem e acabamos tomando-as como verdadeiras, hoje em dia, na comunidade científica, a mente é o cérebro e poucos se atrevem a contrariar isso. Por isso, ainda existem crenças religiosas que pregam algum tipo de dualismo, isto é, a separação entre mente e cérebro, "a neurociência nos diz que elas podem não ser nada além de eventos cerebrais ou até mesmo experiências induzidas no cérebro humano a partir da ingestão de algumas drogas com efeitos específicos" 29 .

Ora, é por saber que estamos pensando, isto é, que temos uma mente que pensa que nós sabemos que estamos a pensar e que existimos como bem notou Descartes. É esse pensar, esses estados subjetivos como, por exemplo, a emoção sentida quando nosso time faz um gol. Essa emoção que não podemos por vezes descrever em poucas palavras ou ainda, nem se quer podemos ver ao olharmos para um cérebro em funcionamento, que fundamentam a nossa linguagem cotidiana sobre aquilo que somos e sentimos. Dessa forma, é através desses conceitos psicológicos que nós diferenciamos aquilo que somos daquilo que não somos e o mesmo acontece com as religiões. Afinal, um dos fatores que faz com que as religiões se mantenham fortes e vivas nos dias de hoje, em meio aos inúmeros avanços técnicos e científicos da sociedade moderna com certeza é essa separação que fazemos entre mente e corpo, entre pensar e agir, ser e parecer, que fazemos sem maiores investigações. Nossa sociedade entende a separação entre a mente e o corpo como algo dado e certo em nosso vocabulário de senso comum. Porque como vimos aqui, identificamos a nós mesmos como sendo fantasmas que habitam máquinas, como salientou Ryle, pois fazemos isso sem maiores problemas e investigações. Fato que se analisado de perto, como fizemos aqui, soa como no mínimo estranho, para não dizer impossível.

\section{Referências}

CHURCHLAND, Paul M. Matéria e consciência: uma introdução contemporânea à filosofia da mente. São Paulo: Editora UNESP, 2004.

COR: FENÔMENO ÓTICO. Universidade Federal do Pará, PR, Abr. 2009. Disponível em:< http://www.ufpa.br/dicas/htm/htm-cor4.htm.>. Acesso em 28 jan. 2013.

COSTA, Claudio. Filosofia da mente. Rio de Janeiro: Jorge Zahar, 2005.

HEIL, John. Filosofia da mente: uma introdução contemporânea. Porto Alegre: Instituto Piaget, 1998.

MASLIN, K. T. Introdução a filosofia da mente. 2. Ed. Porto Alegre: Artmed, 2009.

MATTHEWS, Eric. Mente: conceitos-chave em filosofia. Porto Alegre: Artmed, 2007.

PLATÃO. Phaedro, 80a-b. In: Hamilton, E. and Cairns. Eds. The colletcted Dialogues of Plato, Princeton, Princeton University press.

. A República. Lisboa: Fundação Calouste Gulbenkian, 2001.

RYLE, Gilbert. Introdução à psicologia: o conceito de espírito, The concept of mind. Lisboa: Moraes Editores, 1970.

TEIXEIRA, João de Fernandes. Como ler filosofia da mente. São Paulo: Paulus, 2008.

Filosofia do cérebro. São Paulo: Paulus, 2012.

${ }^{29}$ TEIXEIRA. Filosofia do cérebro. São Paulo: Paulus, 2012, p. 13.

\begin{tabular}{|c|c|c|c|c|c|}
\hline intuitio & $\begin{array}{c}\text { ISSN } \\
1983-4012\end{array}$ & Porto Alegre & Vol.7 $-\mathrm{N}^{\circ} .2$ & $\begin{array}{c}\text { Novembro } \\
2014\end{array}$ & p.89-103 \\
\hline
\end{tabular}


A filosofia da mente de Platão e a imortalidade da mente: um dualismo substancial

Recebido em: 30/04/2014

Aprovado para publicação em: 06/09/2014 